\title{
Anti-HSV-2 activity of Terminalia chebula Retz extract and its constituents, chebulagic and chebulinic acids
}

\author{
Ajay Kesharwani ${ }^{1,3}$, Suja Kizhiyedath Polachira ${ }^{2}$, Reshmi Nair ${ }^{2}$, Aakanksha Agarwall $^{1}$ Nripendra Nath Mishra ${ }^{1}$ \\ and Satish Kumar Gupta ${ }^{*^{*}}$
}

\begin{abstract}
Background: Development of new and effective therapeutics for sexually transmitted herpes simplex virus-2 (HSV2) infection is important from public health perspective. With an aim to identify natural products from medicinal plants, in the present study, the potential of Terminalia chebula Retz was investigated for its activity against HSV-2.

Methods: Fruits of Terminalia chebula Retz were used to prepare 50\% ethanolic extract. In addition, chebulagic acid and chebulinic acid both purified from T. chebula were also used. The extract as well as purified compounds were first used to determine their in vitro cytotoxicity on Vero cells by MTT assay. T. chebula extract, chebulagic acid, chebulinic acid along with acyclovir were subsequently assessed for direct anti-viral activity, and their ability to inhibit attachment and penetration of HSV-2 to the Vero cells. In addition, their anti-HSV-2 activity was also determined by in vitro post-infection plaque reduction assay.

Results: Cytotoxicity assay using Vero cells revealed $C C_{50}=409.71 \pm 47.70 \mu \mathrm{g} / \mathrm{ml}$ for the extract whereas chebulagic acid and chebulinic acid showed more than $95 \%$ cell viability up to $200 \mu \mathrm{g} / \mathrm{ml}$. The extract from T. chebula $\left(I C_{50}=0.01 \pm 0.0002 \mu \mathrm{g} / \mathrm{ml}\right)$, chebulagic $\left(I C_{50}=1.41 \pm 0.51 \mu \mathrm{g} / \mathrm{ml}\right)$ and chebulinic acids $\left(I C_{50}=0.06 \pm 0.002 \mu \mathrm{g} / \mathrm{ml}\right)$ showed dose dependent potent in vitro direct anti-viral activity against HSV-2. These also effectively prevented the attachment as well as penetration of the HSV-2 to Vero cells. In comparison, acyclovir showed poor direct anti-viral activity and failed to significantly $(p>0.05)$ prevent the attachment as well as penetration of HSV-2 to Vero cells when tested upto $50 \mathrm{\mu g} / \mathrm{ml}$. However, in post-infection plaque reduction assay, T. chebula extract, chebulagic and chebulinic acids showed $\mathrm{IC}_{50}$ values of $50.06 \pm 6.12,31.84 \pm 2.64$, and $8.69 \pm 2.09 \mu \mathrm{g} / \mathrm{ml}$, respectively, which were much lower than acyclovir $(71.80 \pm 19.95 \mathrm{ng} / \mathrm{ml})$.

Conclusions: The results presented herein suggest that $T$. chebula extract, chebulagic and chebulinic acids have higher direct antiviral activity against HSV-2 and efficacy to inhibit virus attachment and penetration to the host cells as compared to acyclovir. However, acyclovir is more potent to inhibit post-infection virus replication. Hence, T. chebula may be a useful candidate for developing alternative therapy for prevention of sexually transmitted HSV-2 infection.
\end{abstract}

Keywords: Anti-HSV-2 activity, Attachment assay, Penetration assay, Post-infection plaque reduction assay, Terminalia chebula

\footnotetext{
* Correspondence: skgupta@nii.ac.in

${ }^{1}$ Reproductive Cell Biology Laboratory, National Institute of Immunology,

Aruna Asaf Ali Marg, New Delhi 110 067, India

Full list of author information is available at the end of the article
} 


\section{Background}

Herpes simplex virus-2 (HSV-2) is a double stranded DNA virus belonging to the family Herpesviridae. It causes genital herpes, contributing to the risk of HIV infection through sexual route $[1,2]$. HSV-2 is sexually transmitted virus and infect 500 million people worldwide and 20-23 million new infections are reported annually [3], http://www.who.int/mediacentre/factsheets/fs400/en/ \#hsv2. Since virus is an intracellular parasite in neural ganglia, it is difficult to completely eliminate it $[1,4]$. Nucleoside derivatives such as acyclovir, valaciclovir, famciclovir and cidafovir have been widely used for the treatment of HSV infection [5]. In addition to high cost, treatment with acyclovir and other related drugs is also associated with the emergence of drug resistant strains [6], which is a major hurdle in the immunocompromised individuals, co-infected with other opportunistic Sexually Transmitted Infections (STIs) such as HIV-1 [7, 8].

Natural products from medicinal plants have been an important source of new biologically effective compounds exhibiting different modes of action against viral infection [9-11]. Terminalia chebula Retz. (T. chebula) is an evergreen flowering tree of the Combretaceae family and extensively used in traditional medicine. Pharmacological studies revealed the inhibitory activity of $T$. chebula on viral infections, such as human immunodeficiency virus type 1 (HIV-1), herpes simplex virus-1 (HSV-1), cytomegalovirus (CMV) and influenza [12-16]. In addition, the extract from $T$. chebula also has anti-bacterial, antifungal, anti-carcinogenic, anti-oxidant, anti-diabetic and anti-aging activities [17]. T. chebula has various phytoconstituents like tannins, flavonoids, sterols, amino acids, fructose, resins and fixed oil etc. However, tannins such as chebulinic acid, chebulagic acid, gallic acid, chebulic acid, corilagin and ellagic acid may constitute $30 \%$ of various phytochemicals $[18,19]$. Though there are several studies on the anti-HSV-1 activity of T. chebula extract and its constituents namely chebulagic acid [15, 20,21], but their activity against HSV-2 needs to be addressed.

Keeping in view of the above, the $50 \%$ ethanolic extract prepared from the fruits of $T$. chebula was evaluated for direct anti-viral activity and its impact on the attachment and penetration of the HSV-2 to the Vero cells. Chebulagic and chebulinic acids from $T$. chebula were also tested in these assays and their activity compared with well known drug, acyclovir. Additionally, the extract and pure compounds were also evaluated for in vitro anti-HSV-2 activity in post-infection plaque reduction assay.

\section{Methods}

Plant material, preparation of $50 \%$ ethanolic extract, and compounds

The fruits of Terminalia chebula were collected from the medicinal plants garden of Ayurveda Research Institute,
Poojappura, Kerala and the identity was confirmed at Ayurveda Research Institute, Trivandrum, Kerala. The voucher specimen (HLL/04/2013) has been kept at Natural Products Division of HLL Lifecare Limited, Trivandrum, Kerala, India. Air and shade dried fruits were grinded and strained through a 30 mesh $(0.5 \mathrm{~mm})$. The finely grinded powder (24 g) was subjected to pressurized sequential extraction using Accelerated Solvent Extractor (ASE 150, Dionex Inc., Sunnyvale, CA, USA) essentially as described previously $[22,23]$. In brief, the material was mixed with diatomaceous earth at 4:1 ratio. The mixture was placed into a sample cell $(100 \mathrm{ml})$ and loaded onto the ASE 150 system. Extraction was performed using $50 \%$ ethanol under pressure (1500 psi) at $60{ }^{\circ} \mathrm{C}$ with a flush volume of $60 \%$ using 2 static cycles. The solvent was then evaporated in a rotary evaporator (Büchi Labortechnik AG, 9230 Flawil, Switzerland). The dried extract was weighed and used for further studies.

Highly pure commercial chebulagic acid and chebulinic acid, both purified from $T$. chebula, were obtained from MP Biomedicals, Ohio, Solon, USA. These compounds were used as reference standard to identify the corresponding peaks in 50\% ethanolic extract prepared from fruits of $T$. chebula as well as to determine their anti-HSV-2 activity in various assays as described below. Both the compounds were dissolved in absolute ethanol $(10 \mathrm{mg} / \mathrm{ml})$ and further dilutions were made in the culture medium before use. Acyclovir (commercial name acycloguanosin) was purchased from Sigma-Aldrich Inc., St. Louis, MO, USA. It was dissolved in dimethyl sulphoxide (DMSO) to make stock solution of $7 \mathrm{mg} / \mathrm{ml}$ and further diluted in culture medium to prepare working concentration (s) prior to use. The final concentration of DMSO was $<0.1 \%$ in various assays where acyclovir was used.

\section{High performance liquid chromatography analysis}

The Reverse Phase High Performance Liquid Chromatography (HPLC; LC Agilent, Agilent Technologies, Boblingen, Germany) of the plant extract was performed using a Reverse phase XTerra RP 18 column $(4.6 \times$ $250 \mathrm{~mm}, 5 \mu \mathrm{m}$; Waters Corporation, Milford, USA) and pure compounds (chebulagic and chebulinic acids) were used as reference standards. HPLC grade solvents were purchased from Merck, Mumbai, India. The solvent system used was $0.01 \%$ orthophosphoric acid in water : acetonitrile $(80: 20)$ with a flow rate of $1 \mathrm{ml} / \mathrm{min}$. The peaks were detected at $272 \mathrm{~nm}$. The extract was prepared at a concentration of $5 \mathrm{mg} / \mathrm{ml}$ and the standards at $1 \mathrm{mg} / \mathrm{ml}$ in the mobile phase solvent system and $20 \mu \mathrm{l}$ of each was injected for analysis. The data was processed using open lab software (Agilent Technologies).

\section{Cells and viruses}

African green monkey kidney cells (Vero cells) were obtained from National Centre of Cell Science, Pune, India 
and maintained in Dulbecco's modified Eagle's medium (DMEM; Sigma-Aldrich Inc.) supplemented with 10\% fetal bovine serum (FBS; Biological Industries, Kibbutz beit HaemeK, Israel) and an antibiotic-antimycotic cocktail [Penicillin (100 units/ml), Streptomycin $(100 \mu \mathrm{g} / \mathrm{ml})$ and Amphotericin B (250 ng/ml); Pen-Strep-Ampho sol, Biological Industries]. For HSV-2 G strain (VR-734; ATCC, Rockville, USA) production, the Vero cell culture was maintained at $37{ }^{\circ} \mathrm{C}$ in a humidified atmosphere of $5 \% \mathrm{CO}_{2}$. The HSV-2 strain was propagated in the 25$\mathrm{cm}^{2}$ tissue culture flask for $72 \mathrm{~h}$ at $37^{\circ} \mathrm{C}$ in $\mathrm{CO}_{2}$ incubator at multiplicity of infection (MOI) of $0.01 \mathrm{PFU} / \mathrm{cell}$ [24]. After three cycles of freezing/thawing, the supernatant was titrated on the basis of Plaque Forming Unit (PFU) as previously described [24] and stored in aliquots at $-80{ }^{\circ} \mathrm{C}$ until use.

\section{Cytotoxicity assay}

The cytotoxicity of the $50 \%$ ethanolic T. chebula extract, chebulagic acid, chebulinic acid and acyclovir was assessed by MTT [3-(4,5-dimethylthiazol-2-yl)-2,5-diphenyltetrazolium bromide; Sigma-Aldrich Inc.] assay [25]. In brief, Vero cells $\left(1.25 \times 10^{4} /\right.$ well $)$ were seeded in 96-well cell culture plates (Greiner Bio-One, GmbH, Frickenhausen, Germany) and grown overnight at $37{ }^{\circ} \mathrm{C}$ in humidified atmosphere of $5 \% \mathrm{CO}_{2}$. After $24 \mathrm{~h}$, cells were treated with varying concentrations of the $T$. chebula extract, chebulagic acid, chebulinic acid and acyclovir in duplicate along with vehicle [dimethyl sulfoxide (DMSO) and/or ethanol] control for $48 \mathrm{~h}$. Negative control included cells with medium only. After incubation, $20 \mu \mathrm{l}$ of MTT $(5 \mathrm{mg} / \mathrm{ml}$ in $50 \mathrm{mM}$ PBS) was added per well and incubated for $4 \mathrm{~h}$ at $37^{\circ} \mathrm{C}$, followed by addition of MTT solvent $(100 \mu \mathrm{l} /$ well; $0.04 \mathrm{~N} \mathrm{HCl}$ in absolute isopropanol). The absorbance (OD) was read at $540 \mathrm{~nm}$ with reference filter at $630 \mathrm{~nm}$ by using microplate spectrophotometer (ELX 800MS; BioTek Instrument Inc., Vermont, USA). Percent viability was calculated by dividing the OD obtained in treatment group by OD in the respective vehicle control multiplied by 100 .

\section{Anti-HSV-2 activity of the extract of $T$. chebula, chebulagic acid and chebulinic acid \\ Direct anti-viral activity assay}

To evaluate direct inactivation of HSV-2 by $50 \%$ ethanolic $T$. chebula extract, chebulagic acid and chebulinic acid, HSV-2 virus (100 PFU) was pre-incubated with sub-toxic serial concentrations of the T. chebula extract, chebulagic acid, chebulinic acid and acyclovir at $37{ }^{\circ} \mathrm{C}$ for $1 \mathrm{~h}$. Subsequently, the contents were added to the confluent Vero cells monolayer growing in a 24-well cell culture plate (Corning Incorporated Costar, NY, USA) followed by incubation at $37{ }^{\circ} \mathrm{C}$ for $1 \mathrm{~h}$ under the humidified 5\% $\mathrm{CO}_{2}$ atmosphere. After virus adsorption, the supernatant was aspirated and infected cells were washed twice with serum free DMEM and overlaid with $1 \%$ low melting point (LMP) agarose overlay medium. After $48 \mathrm{~h}$ incubation, cells were fixed with $10 \%$ formaldehyde (in $50 \mathrm{mM}$ PBS), stained with $0.2 \%$ crystal violet and number of plaques counted. The percent plaque reduction was calculated as $100-\left[\left(P_{\mathrm{T}} / P_{\mathrm{C}}\right) \times 100\right]$, where $P_{\mathrm{T}}$ and $P_{\mathrm{C}}$ refer to the number of plaques in the presence and absence of the compound, respectively. The direct anti-viral activity was measured by plaque reduction as compared to the vehicle treated virus control. The minimal concentration of the compound required to inhibit $50 \%$ of plaque numbers $\left(\mathrm{IC}_{50}\right)$ was calculated by regression analysis of the dose-response curves of the extract/compounds.

\section{HSV-2 attachment and penetration assay}

The attachment and penetration assays were performed essentially as described previously [26, 27] with slight modifications. In brief, for attachment assay, confluent Vero cells grown in 24-well cell culture plates were prechilled at $4{ }^{\circ} \mathrm{C}$ for $1 \mathrm{~h}$. The medium was aspirated and virus (100 PFU/well) was added in the presence or absence of the varying concentrations of $50 \%$ ethanolic $T$. chebula extract, chebulagic acid, chebulinic acid and acyclovir to the Vero cells and incubated for $3 \mathrm{~h}$ at $4{ }^{\circ} \mathrm{C}$. Subsequently, cells were washed twice with plain DMEM medium, and processed as described in direct anti-viral activity assay to determine $\mathrm{IC}_{50}$. In the penetration assay, HSV-2 virus (100 PFU/well) was added to the pre-chilled confluent monolayer of Vero cells growing in 24-well culture plate for $3 \mathrm{~h}$ at $4{ }^{\circ} \mathrm{C}$ to allow attachment. The medium was replaced with pre-warmed fresh medium containing varying concentrations of test extract/compounds and incubated at $37^{\circ} \mathrm{C}$ to maximize virus penetration. After $30 \mathrm{~min}$, the infected monolayer cultures were treated with warm PBS ( $\mathrm{pH}$ 3.0) for 1 min to inactivate the non-penetrated viruses. After washing three times with serum-free medium, cells were overlaid with $1 \%$ LMP agarose and processed to quantitate the number of plaques after $48 \mathrm{~h}$ incubation as described above.

\section{Post-infection virus plaque reduction assay}

The anti-HSV-2 activity of 50\% ethanolic T. chebula extract, chebulagic acid, chebulinic acid and acyclovir has been evaluated by using post-infection plaque reduction assay [28]. In brief, Vero cells $\left(8 \times 10^{4} /\right.$ well $)$ were seeded in 24-well cell culture plate and incubated at $37^{\circ} \mathrm{C}$ in a humidified atmosphere of $5 \% \mathrm{CO}_{2}$ to form complete monolayer. After incubation, medium was removed and cells were infected with HSV-2 virus (100 PFU/well) for $1 \mathrm{~h}$ at $37{ }^{\circ} \mathrm{C}$ under humidified atmosphere of $5 \% \mathrm{CO}_{2}$. After virus adsorption, viral inocula was subsequently removed by washing the cells twice with fresh serum 
free DMEM and cells were overlaid with 1\% LMP agarose, containing varying concentrations (less than calculated $\mathrm{CC}_{50}$ values) of the $50 \%$ ethanolic extract from $T$. chebula, chebulagic acid and chebulinic acid. Acyclovir was used as positive control and agar overlay containing appropriate solvents (DMSO/ethanol), used to prepare test compounds comprises the vehicle control. After $48 \mathrm{~h}$ incubation, plates were processed and number of plaques counted.

\section{Statistical analysis}

The values are expressed as mean \pm standard error mean of three/four independent experiments performed in duplicate. For determination of the $\mathrm{CC}_{50}$ and $\mathrm{IC}_{50}$ values, nonlinear regression of concentration-response curves were prepared using GraphPad Prism 4 (GraphPad Software Inc., CA, USA). The statistical significance in reduction of plaques in presence of $T$. chebula extract, chebulagic acid, chebulinic acid and acyclovir versus respective vehicle treated virus control was determined by one-way ANOVA and $p<0.05$ was considered statistically significant. Significance among various treatment groups was further analysed by using Tukey post-hoc test.

\section{Results}

\section{T. chebula extract, chebulagic acid and chebulinic acid} showed potent direct anti-viral activity

The $50 \%$ ethanolic extract from the fruits of T. chebula was prepared as described in Methods. From 24 g powder, the average yield of $50 \%$ ethanolic extract was $15 \mathrm{~g}$ (62.5\% yield). Analysis of T. chebula extract by reverse phase HPLC revealed multiple peaks, furthermore chebulagic acid and chebulinic acid revealed a retention time of 11.2 and $29.2 \mathrm{~min}$, respectively (Fig. 1). In addition to these two major peaks, peak with retention time of 3.4 min corresponded to gallic acid (Fig. 1).

Before evaluating the anti-HSV-2 activity of the 50\% ethanolic extract prepared from the fruits of T. chebula or compounds chebulagic acid and chebulinic acid, their effect on the viability of Vero cells was determined by MTT assay as described in Methods. The extract of $T$. chebula revealed $409.71 \pm 47.70 \mu \mathrm{g} / \mathrm{ml} \quad \mathrm{CC}_{50}$ value (Table 1). The chebulagic and chebulinic acids showed $>$ $95 \%$ cell viability when tested up to $200 \mu \mathrm{g} / \mathrm{ml}$. The $\mathrm{CC}_{50}$ value of $351.85 \pm 48.80 \mu \mathrm{g} / \mathrm{ml}$ was observed with acyclovir (Table 1).

Anti-HSV-2 activity by direct inactivation of the virus was tested in the presence of crude extract/compounds. HSV-2 virus was pre-treated with varying concentrations of $T$. chebula extract, chebulagic acid, chebulinic acid and acyclovir followed by analysis of their ability to infect Vero cells by formation of plaques as described in Methods. The pre-treatment of HSV-2 with the plant extract, chebulagic acid as well as chebulinic acid showed a significant reduction in the formation of plaques as compared to vehicle treated virus control group with $\mathrm{IC}_{50}$ values of $0.01 \pm 0.0002,1.41 \pm 0.51$, and $0.06 \pm$ $0.002 \mu \mathrm{g} / \mathrm{ml}$ respectively (Table 1 ). The differential anti-HSV-2 activity of the above treatment groups with respect to each other was not significant using one way ANOVA. The direct antiviral activity of the T. chebula extract, chebulagic acid and chebulinic acid was approximately 20 to 2900 fold higher than acyclovir $\left(\mathrm{IC}_{50}=29.04 \pm 1.04 \mu \mathrm{g} / \mathrm{ml}\right.$; Table 1$)$.

\section{T. chebula extract, chebulagic acid and chebulinic acid effectively inhibited HSV-2 attachment and penetration to the Vero cells}

Further, the effect of $T$. chebula extract, chebulagic acid, chebulinic acid and acyclovir was also evaluated on the attachment and penetration of HSV-2 to the Vero cells as described in Methods. T. chebula extract, chebulagic acid and chebulinic acid significantly inhibited in vitro binding of HSV-2 to Vero cells in a dose-dependent manner with the $\mathrm{IC}_{50}$ values of $0.48 \pm 0.20,1.66 \pm 0.30$, and $0.29 \pm 0.01 \mu \mathrm{g} / \mathrm{ml}$ as compared to vehicle treated virus control respectively (Fig. 2). The differences among the treatment groups of plant extract, chebulagic acid and chebulinic acid for inhibition of HSV-2 attachment to Vero cells was significant by one way ANOVA analysis. Furthermore, analysis by Tukey post-hoc test revealed that anti-HSV-2 activity in the attachment assay by chebulinic acid was significantly higher than chebulagic acid. Acyclovir, when tested up to a concentration of $50 \mu \mathrm{g} / \mathrm{ml}$ did not show any significant $(p>0.05)$ inhibition in the HSV-2 binding to Vero cells as revealed by the number of plaques observed as compared to DMSO treated negative control (Fig. 2). Further, pre-treatment of the Vero cells with the $10 \mu \mathrm{g} / \mathrm{ml}$ of $T$. chebula extract, chebulagic acid \& chebulinic acid and $1 \mu \mathrm{g} / \mathrm{ml}$ of acyclovir followed by infection with HSV-2 did not show any significant reduction in the number of viral plaques as compared to vehicle treated cells, suggesting that the above extract/compounds do not have any inhibitory effect on the host cell receptors (data not shown).

In addition to the attachment assay, we also observed a concentration dependent significant inhibition of HSV2 penetration to the Vero cells by the T. chebula extract, chebulagic acid and chebulinic acid with the $\mathrm{IC}_{50}$ values of $0.99 \pm 0.52 \mu \mathrm{g} / \mathrm{ml}, 4.65 \pm 0.02 \mu \mathrm{g} / \mathrm{ml}$, and $0.68 \pm$ $0.05 \mu \mathrm{g} / \mathrm{ml}$ respectively with respect to vehicle treated virus control (Fig. 3). The differences among the treatment groups of plant extract, chebulagic acid and chebulinic acid for inhibition of HSV-2 penetration in the Vero cells was significant by one way ANOVA analysis. Further analysis of the data by Tukey post-hoc test revealed significant differences between chebulagic acid treatment group with respect to plant extract or chebulinic acid treatment 


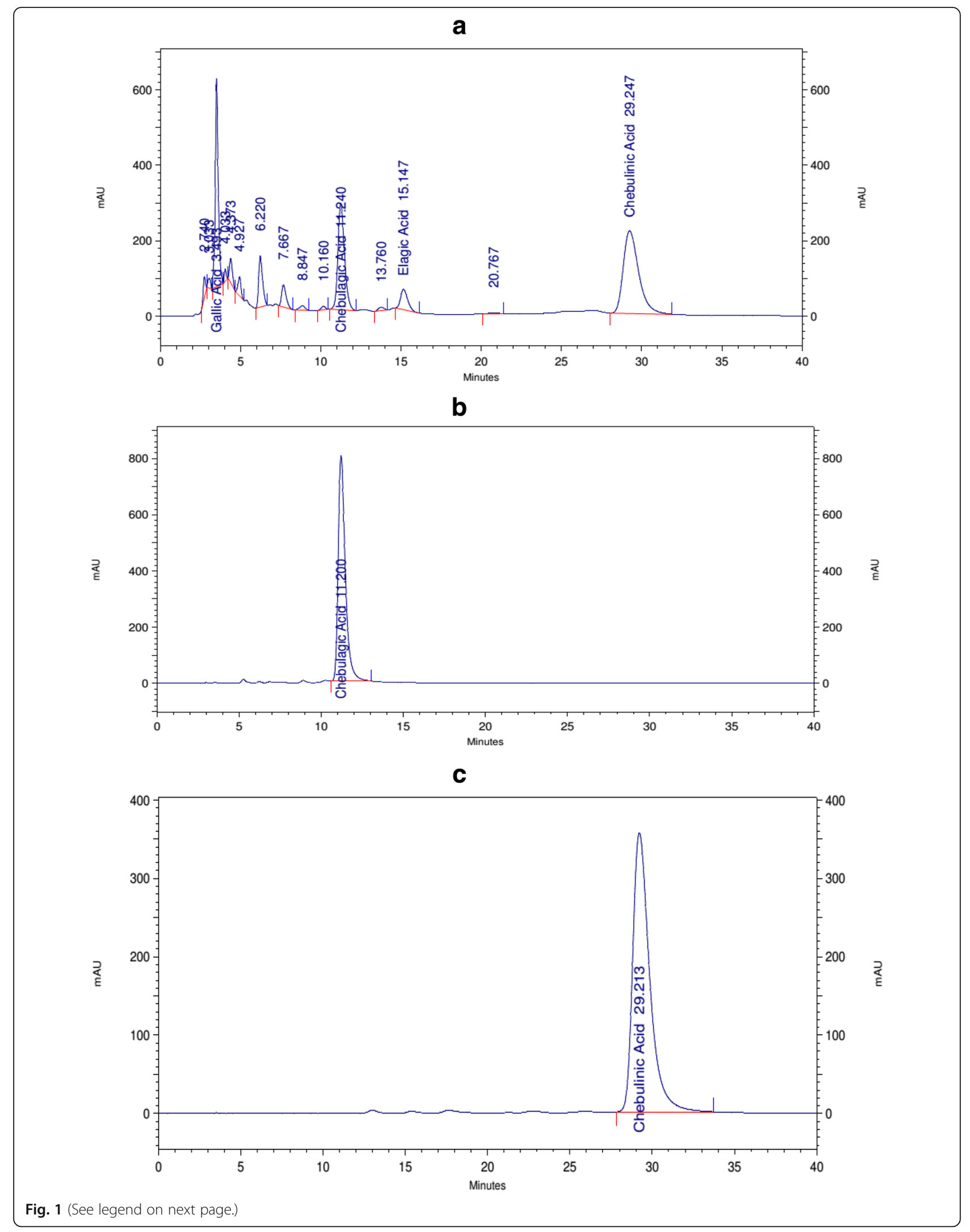


(See figure on previous page.)

Fig. $1 \mathrm{HPLC}$ profiles of 50\% ethanolic extract prepared from the fruits of T. chebula, chebulagic acid and chebulinic acid. The crude extract prepared from the fruits of T. chebula $(100 \mu \mathrm{g})$, chebulagic acid $(20 \mu \mathrm{g})$ and chebulinic acid $(20 \mu \mathrm{g})$ were resolved by reverse phase HPLC using RP 18 column as described in Methods. The X-axis represents the time (min) and Y-axis represents the voltage (mAU) at $272 \mathrm{~nm}$. Solvent used was acetonitrile: $\mathrm{H}_{2} \mathrm{O}(20: 80 \mathrm{v} / \mathrm{v})$ supplemented with $0.01 \%$ orthophosphoric acid. a $50 \%$ ethanolic extract prepared from the fruits of $T$. chebula, b chebulagic acid and (c) chebulinic acid. The peak corresponding to gallic acid in panel (a) was identified by running gallic acid standard (data not shown)

groups. However, no significant difference was observed between plant extract versus chebulinic acid treatment group. As in attachment assay, chebulinic acid in the penetration assay also showed highest anti-HSV-2 activity. Acyclovir $(50 \mu \mathrm{g} / \mathrm{ml})$ did not reveal any significant $(p>0.05)$ decrease in HSV-2 penetration to the Vero cells under similar experimental conditions (Fig. 3).

\section{T. chebula extract, chebulagic acid and chebulinic acid showed reduced anti-HSV-2 activity as compared to acyclovir in post-infection plaque reduction assay} In the post-infection plaque reduction assay, acyclovir showed dose dependent significant inhibition of HSV-2 replication with an $\mathrm{IC}_{50}$ value of $71.80 \pm 19.95 \mathrm{ng} / \mathrm{ml}$ (Fig. 4). However, extract $\left(\mathrm{IC}_{50}=50.06 \pm 6.12 \mu \mathrm{g} / \mathrm{ml}\right)$ as well as chebulagic $\left(\mathrm{IC}_{50}=31.84 \pm 2.64 \mu \mathrm{g} / \mathrm{ml}\right)$ and chebulinic $\left(\mathrm{IC}_{50}=8.69 \pm 2.09 \mu \mathrm{g} / \mathrm{ml}\right)$ acids showed approximately $120-700$ fold lower $\mathrm{IC}_{50}$ values as compared to acyclovir in the post-infection plaque reduction assay (Fig. 4). Using Tukey post-hoc test, chebulinic acid showed significantly higher anti-HSV-2 activity as compared to plant extract as well as chebulagic acid. However, anti-HSV-2 activity was not significantly different between plant extract versus chebulagic acid.

\section{Discussion}

In the present study, we have shown that the $50 \%$ ethanolic extract prepared from the fruits of T. chebula has a very potent direct antiviral activity against HSV-2 (Table 1). The direct anti-viral activity of the aqueous extract prepared from the seeds of $T$. chebula on influenza A (H3N8) virus has also been reported [16].

Table 1 Cytotoxicity and direct antiviral activity against HSV-2 of the $50 \%$ ethanolic extract prepared from fruits of T. chebula, chebulagic acid, chebulinic acids and acyclovir in Vero cells

\begin{tabular}{lll}
\hline Test compounds & ${ }^{\mathrm{a}} \mathrm{CC}_{50}(\mu \mathrm{g} / \mathrm{ml})$ & ${ }^{\mathrm{b}} \mathrm{C} \mathrm{C}_{50}(\mu \mathrm{g} / \mathrm{ml})$ \\
\hline T. chebula 50\% ethanolic extract & $409.71 \pm 47.70$ & $0.01 \pm 0.0002$ \\
Chebulagic acid & $>200^{\mathrm{c}}$ & $1.41 \pm 0.51$ \\
Chebulinic acid & $>200^{\mathrm{c}}$ & $0.06 \pm 0.002$ \\
Acyclovir & $351.85 \pm 48.80$ & $29.04 \pm 1.04$
\end{tabular}

Values in this table represent the mean \pm SE of four independent experiments performed in duplicate

${ }^{\mathrm{a}} \mathrm{CC}_{50}$ was the concentration that showed viability of $50 \%$ of the Vero cells

${ }^{{ }}{ }_{\mathrm{C}} \mathrm{C}_{50}$ was the concentration that inhibited $50 \%$ of HSV-2 activity in direct anti- viral activity assay using Vero cells as host

c $>95 \%$ cells were viable at $200 \mu \mathrm{g} / \mathrm{ml}$
Casuarinin, a hydrolyzable tannin isolated from the bark of Terminalia arjuna Linn also showed potent virucidal activity against HSV-2 at a concentration of $25 \mu \mathrm{M}$ [29]. The observed direct anti-viral activity by the two hydrolyzable tannins namely chebulagic acid and chebulinic acid purified from T. chebula against HSV-2 is reported for the first time, which seems to be higher than casuarinin. The direct anti-viral activity of T. chebula extract, chebulagic acid and chebulinic acid was also significantly $(p<0.05)$ higher than acyclovir, a well known drug used for the treatment of HSV infection. We speculate that the direct anti-viral activity of $T$. chebula extract, chebulagic acid and chebulinic acid may be due to their interaction with viral surface glycoproteins, causing alteration in its function or by making virus particles inert and prevent their attachment and spreading to the Vero cells. Indeed hydrolyzable tannins such as chebulagic acid and punicalagin have been shown to bind to glycoproteins of various viruses thereby inhibiting their entry to the host cells as well as prevent cell-to-cell spread $(20,21)$.

HSV requires its glycoproteins $(\mathrm{gB}, \mathrm{gC}, \mathrm{gD}, \mathrm{gH}$ and $\mathrm{gL})$ to interact with the host cell receptors (heparan sulphate, nectin- 1 and nectin-2) followed by penetrating the membrane by fusion process $[30,31]$. T. chebula extract, chebulagic acid and chebulinic acid showed potent inhibition of HSV-2 attachment (Fig. 2) as well as penetration (Fig. 3) to Vero cells. It has been shown that casuarinin, inhibited the attachment and penetration of HSV-2 to Vero cells broadly through the disturbances of the viral glycoproteins [29]. Chebulagic acid and punicalagin, the hydrolyzable tannins isolated from the fruits of $T$. chebula, inhibited HSV-1 viral particles and prevented their binding, penetration and cell-to-cell spread, as well as secondary infection [20]. However, pre-treatment of the host cells with chebulagic acid and punicalagin were not effective in prevention of HSV-1 infection. Their inhibitory activities targeted HSV-1 glycoproteins involved in the attachment and membrane fusion, by blocking interaction with host cell surface glycosaminoglycans. Antiviral activity of chebulagic acid and punicalagin was significantly reduced in mutant cell lines deficient for heparan sulfate and chondroitin sulfate suggesting that these tannins may be interfering in the interaction of HSV-1 glycoproteins with heparan sulfate/chondroitin sulfate rather than lysis of viral membrane [20]. It is likely that the T. chebula extract, chebulagic acid and chebulinic acid also target HSV-2 

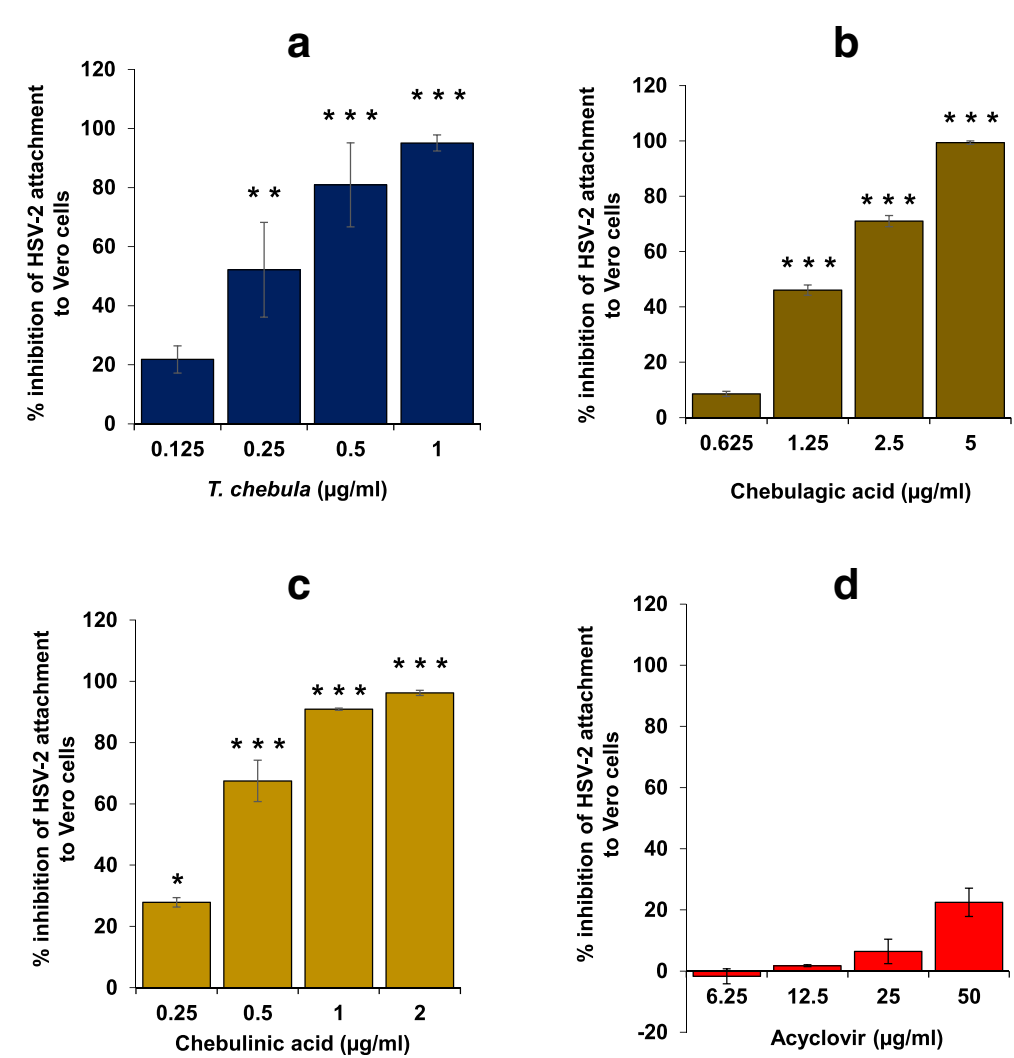

Fig. 2 Efficacy of the T. chebula extract, chebulagic acid, chebulinic acid and acyclovir to inhibit attachment of HSV-2 to Vero cells. HSV-2 (100 PFU) virus along with various concentrations of the T. chebula extract, chebulagic acid, chebulinic acid and acyclovir was incubated for $3 \mathrm{~h}$ with the pre-chilled Vero cells seeded in 24-well plates at $4{ }^{\circ} \mathrm{C}$ and processed for inhibition in the attachment of the virus as described in Methods. The Y-axis represents percent inhibition in the number of plaques with respect to the vehicle treated virus control group. Values are expressed as mean \pm SEM of the three independent experiments performed in duplicate. Various panels are (a) extract of $T$. chebula, b chebulagic acid, $\mathbf{c}$ chebulinic acid and (d) acyclovir. ${ }^{*} p \leq 0.05,{ }^{* *} p \leq 0.01$, and ${ }^{* * *} p \leq 0.001$ between treated and vehicle control at respective concentration of the extract/compound

glycoproteins that are responsible for its binding to host cell receptors. Failure of acyclovir to show any significant decrease in the attachment as well as penetration of HSV2 to the host cells may be due to the fact that it primarily works intra-cellularly by inhibiting virus replication.

The results shown in the present study revealed that $50 \%$ ethanolic extract prepared from the fruits of T. chebula, chebulagic acid and chebulinic acid also inhibited post-fusion HSV-2 replication or spread to other cells, which was approximately 120-700 fold lower as compared to acyclovir. Keeping in view of the large molecular weight of chebulagic acid and chebulinic acid, it is likely that they may not penetrate the Vero cells and hence may not interfere in intracellular virus replication. In contrast, acyclovir will enter the cells and inhibit HSV-2 replication. Acyclovir is converted in the virus infected cells to acyclovir monophosphate using viralencoded thymidine kinase and subsequently to acyclovir triphosphate by using host cell enzymes, which prevent virus DNA synthesis and thus replication by inhibiting the viral DNA polymerase [32]. It is likely that $T$. chebula extract, chebulagic acid and chebulinic acid binds to viral glycoproteins expressed on the infected Vero cell surface thereby rendering their unavailability for cell-to-cell spread. However, further studies will be required to understand the plausible mechanism by which $T$. chebula extract, chebulagic acid and chebulinic acid exhibit anti-HSV-2 activity in the post-infection plaque reduction assay.

T. chebula fruit is one of the important ingredients of Triphala-an important herbal preparation used for centuries in the traditional Indian system of Ayurveda as colon cleanser, digestive, diuretic and laxative [33]. The extract prepared from the fruits of T. chebula or its constituents have shown diverse pharmacological activities which include, antioxidant and free radical scavenging activity, anticarcinogenic activity, hepatoprotective activity, cardioprotective activity, cytoprotective activity, antidiabetic activity, antibacterial, fungal and viral activity, gasterointestinal motility improving and anti-ulcerogenic activity etc. $[17,34-38]$. Keeping in view of its acetylcholinestrase inhibitors activity, antioxidant and anti-inflammatory effects, 

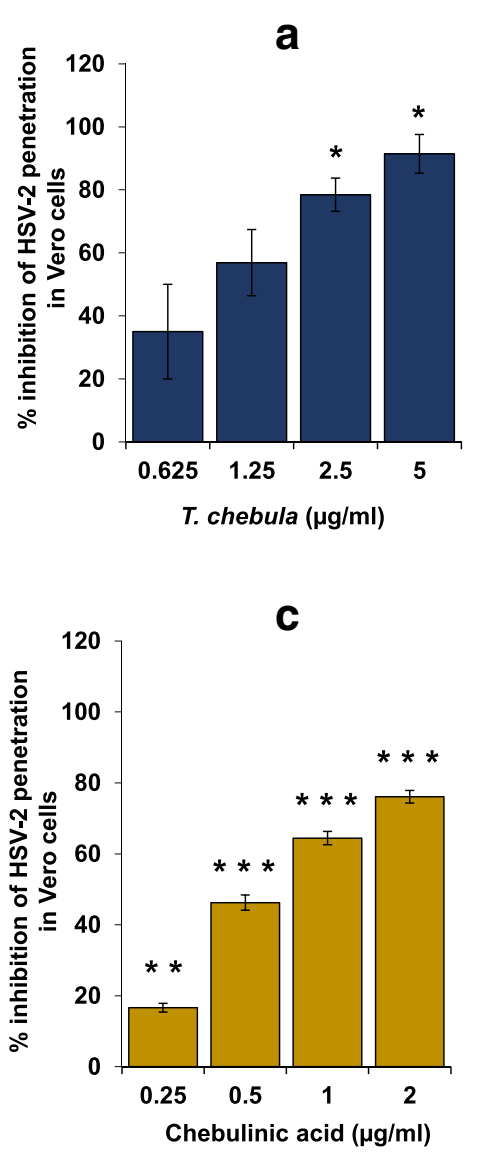

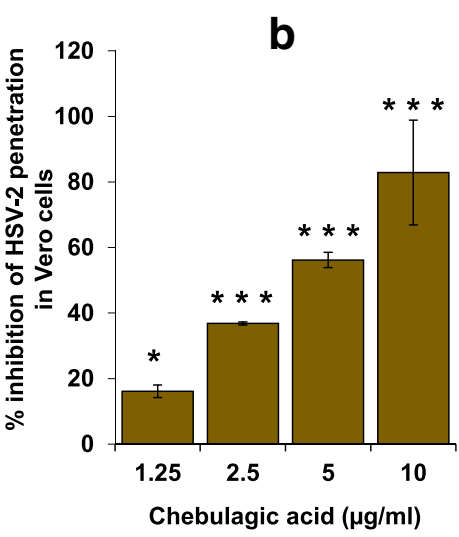

d

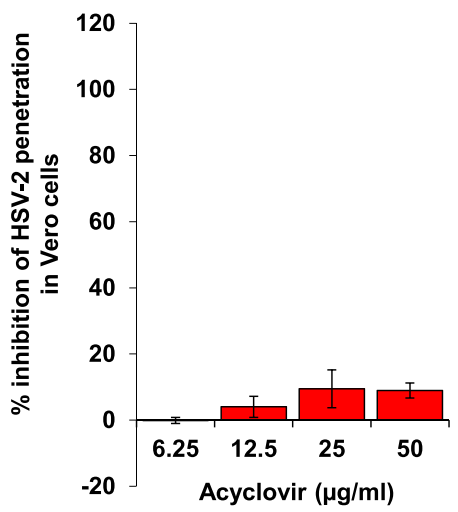

Fig. 3 Efficacy of the T. chebula extract, chebulagic acid, chebulinic acid and acyclovir to inhibit penetration of HSV-2 to Vero cells. Pre-chilled confluent monolayer of Vero cells growing in 24-well culture plate were incubated with HSV-2 (100 PFU) for 3 h at $4{ }^{\circ} \mathrm{C}$ followed by incubation with the varying concentrations of the extract of T. chebula (a), chebulagic acid (b), chebulinic acid (c) and acyclovir (d) at $37{ }^{\circ} \mathrm{C}$ for 30 min to allow virus penetration followed by assessment of plaque formation as described in Methods. Values are expressed as percent inhibition in the number of plaques as compared to vehicle treated virus control. Each bar represents the mean \pm SEM of three independent experiments performed in duplicate. ${ }^{*} p \leq 0.05$, ${ }^{* *} p \leq 0.01$, and ${ }^{* * *} p \leq 0.001$ between treated and vehicle control at respective concentration of the extract/compound

its potential for the treatment of alzheimer's disease is also being explored [39]. Interestingly, in vivo anti-viral property of chebulagic acid, was also demonstrated by treating mice challenged with a lethal dose of human enterovirus 71 (major causative agent of hand, foot and mouth disease in younger children), which led to reduce mortality and clinical symptoms mediated by inhibiting viral replication [40]. In another study, the extract prepared from T. chebula Retz when administered along with acyclovir significantly curtailed the development of skin lesion and prolonged the mean survival rate of $\mathrm{HSV}-1$ infected mice as compared to when administered either acyclovir or herbal extract alone [15]. These studies suggest the enormous clinical potential of $T$. chebula for a variety of ailments. The obvious question comes to mind about the safety of the $T$. chebula-based herbal preparations. The ethanolic extract of $T$. chebula fruits did not show any mutagenic properties as tested in bacterial mutation assays and also did not reveal any toxic effects when repeatedly administered orally in rats [41]. The anti-mutagenic activity of the hydrolyzable tannins purified from $T$. chebula has also been shown by another independent study [42]. The fruits from $T$. chebula could reduce the lead and almunium induced genotoxicity [38]. These studies suggest that $T$. chebula extract and hydrolyzable tannins are safe molecules to be used as therapeutic agents against HSV. In contrast, a known side effect of prolonged treatment with acyclovir is nephrotoxicity [43]. However, the extract of $T$. chebula has nephroprotective activity [44]. Use of $T$. chebula extract, chebulagic and chebulinic acids could improve the prognosis of sexually transmitted HSV-2 as well as reduction of sexually transmitted HIV-1 as co-infection. The extract of T. chebula will also be useful against viruses that use glycosaminoglycans as entry door in to the host such as Hepatitis C, HIV and dengue viruses. However, extensive investigations are needed to exploit its therapeutic potential for drug resistant viruses. 

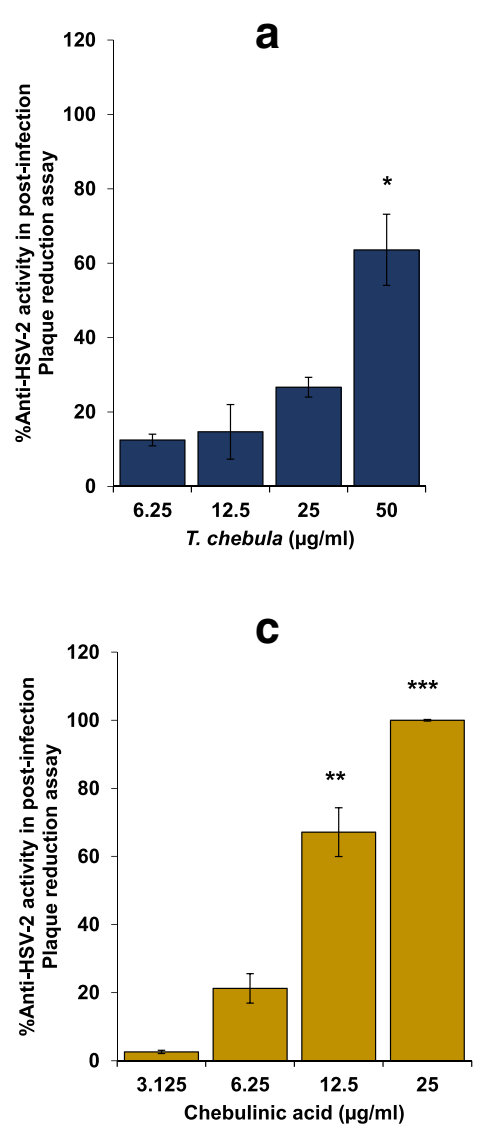
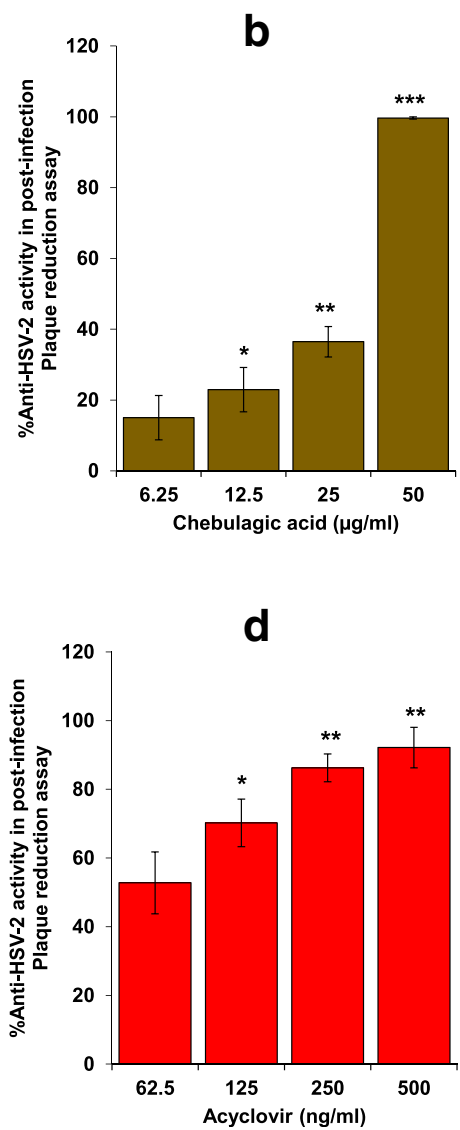

Fig. 4 Anti-HSV-2 activity of the T. chebula extract, chebulagic acid, chebulinic acid and acyclovir in post-infection plaque reduction assay. Vero cells growing as monolayer in 24-well culture plate were infected with HSV-2 (100 PFU/well) followed by 1\% low melting point agarose overlay medium containing varying concentration of the $50 \%$ ethanolic extract of T. chebula, chebulagic acid, chebulinic acid and acyclovir. After $48 \mathrm{~h}$ incubation, plates were processed to assess the number of plaques as described in Methods. The Y-axis represents percent inhibition in the number of plaques with respect to the vehicle treated virus control group and X-axis the concentration of the test extract/compounds. Each bar represents mean \pm SEM of the three independent experiments performed in duplicate. Various panels are $\mathbf{a}$ extract of $T$. chebula, $\mathbf{b}$ chebulagic acid, $\mathbf{c}$ chebulinic acid and $\mathbf{d}$ acyclovir. ${ }^{*} p \leq 0.05,{ }^{* *} p \leq 0.01$, and ${ }^{* * *} p \leq 0.001$ respectively between treated and vehicle control at tested concentration of the extract/compound

\section{Conclusions}

To the best of our knowledge, we have demonstrated for the first time, anti-HSV-2 activity of T. chebula. Due to potent direct antiviral activity against HSV-2 including its attachment as well as penetration by $T$. chebula extract, chebulagic acid and chebulinic acid, which is higher than acyclovir, this plant may be a good source to identify natural product (s). However, additional studies will be required to determine the mechanism by which $T$. chebula and its constituents exhibit anti-HSV-2 activity.

\section{Abbreviations}

ASE: Accelerated solvent extractor; $\mathrm{CC}_{50}$ : Concentration that shows $50 \%$ of cytotoxic effect; CMV: Cytomegalovirus; DMEM: Dulbecco's modified Eagle's medium; DMSO: Dimethyl sulfoxide; FBS: Fetal bovine serum; HIV: Human immunodeficiency virus; HPLC: High Performance Liquid Chromatography; HSV: Herpes simplex virus; $\mathrm{IC}_{50}$ : Inhibitory concentration producing $50 \%$ reduction in plaque formation; LMP: Low melting point; MOl: Multiplicity of infection; MTT: 3-(4,5-dimethylthiazole-2-yl)-2-5-diphenyltetrazolium bromide; PFU: Plaque forming unit; STI: Sexually transmitted infection

\section{Acknowledgements}

We would like to acknowledge Mr. Rajit Ram, Technical Officer, Reproductive Cell Biology Lab, National Institute of Immunology, New Delhi for providing help in preparing the culture medium and maintenance of the cell culture facility. We would also like to thank Prof. R. N. Pandey, Head, Department of Biostatics, All India Institute of Medical Sciences, New Delhi, India for help in analysis of data using Tukey post-hoc test.

\section{Funding}

This study was financially supported by the research grants from the Department of Biotechnology (BT/PR5691/MED/108/11/2012), Government of India and Indian Council of Medical Research (5/7/853/12-RCH), Government of India. SKG would like to acknowledge J. C. Bose Fellowship (SB/S2/JCB-040/2015) by Science and Engineering Research Board, Department of Science and Technology, Government of India. The views expressed by the authors, does not necessarily reflect the views of the funding agencies.

\section{Availability of data and materials}

The $50 \%$ ethanolic extract prepared from the fruits of T. chebula Retz has been deposited as voucher specimen (HLL/04/2013) and will be available from Natural Products Division, HLL Lifecare Limited, Trivandrum, Kerala, India. 


\section{Authors' contributions}

AK performed the antiviral assays and analysed the data statistically. KPS and RN collected the plant material, prepared crude extract and analysed it by HPLC. AA and NNM participated in the experimental work and helped in manuscript writing. SKG supervised the work, interpreted the results and wrote the manuscript. All authors contributed accordingly and approved the final manuscript.

\section{Competing interests}

The authors declare that they have no competing interests.

\section{Consent for publication}

Not applicable.

\section{Ethics approval and consent to participate}

Not applicable.

\section{Author details}

'Reproductive Cell Biology Laboratory, National Institute of Immunology, Aruna Asaf Ali Marg, New Delhi 110 067, India. ${ }^{2}$ Corporate R \& D Centre, HLL Lifecare Limited, Akkulum, Thiruvananthapuram, Kerala 695 017, India. ${ }^{3}$ Present Address: Anatomy and Cell Biology, Medical Faculty, Saarland University, Homburg, Saar, Germany.

Received: 24 June 2016 Accepted: 2 February 2017

Published online: 14 February 2017

\section{References}

1. Brugha R, Keersmaekers K, Renton A, Meheus A. Genital herpes infection: a review. Int J Epidemiol. 1997;26:698-709.

2. Severson JL, Tyring SK. Relation between herpes simplex viruses and human immunodeficiency virus infections. Arch Dermatol. 1999:135:1393-97.

3. Looker KJ, Garnett GP, Schmid GP. An estimate of the global prevalence and incidence of herpes simplex virus type 2 infection. Bull World Health Organ. 2008:86:805-12.

4. Whitley RJ, Roizman B. Herpes simplex virus infections. Lancet. 2001:357:1513-8.

5. Cassady KA, Whitley RJ. New therapeutic approaches to the alphaherpesvirus infections. J Antimicrob Chemother. 1997:39:119-28.

6. Englund JA, Zimmerman ME, Swierkosz EM, Goodman JL, Scholl DR, Balfour $\mathrm{HHJ}$. Herpes simplex virus resistant to acyclovir. A study in a tertiary care center. Ann Intern Med. 1990;112:416-22.

7. Erlich KS, Mills J, Chatis P, Mertz GJ, Busch DF, Follansbee SE, et al. Acyclovirresistant herpes simplex virus infections in patients with the acquired immunodeficiency syndrome. N Engl J Med. 1989;320:293-6.

8. Bean B. Antiviral therapy: current concepts and practices. Clin Microbiol Rev. 1992;5:146-82

9. De Clercq E. Current lead natural products for the chemotherapy of human immunodeficiency virus (HIV) infection. Med Res Rev. 2000;20: 323-49.

10. Newman DJ, Cragg GM, Snader KM. Natural products as sources of new drugs over the period 1981-2002. J Nat Prod. 2003:66:1022-37.

11. Kitazato K, Wang Y, Kobayashi N. Viral infectious disease and natural products with antiviral activity. Drug Discov Ther. 2007;1:14-22.

12. el Mekkawy S, Meselhy MR, Kusumoto IT, Kadota S, Hattori M, Namba T. Inhibitory effects of Egyptian folk medicines on human immunodeficiency virus (HIV) reverse transcriptase. Chem Pharm Bull. 1995;43:641-8.

13. Yukawa TA, Kurokawa M, Sato H, Yoshida Y, Kageyama S, Hasegawa T, et al. Prophylactic treatment of cytomegalovirus infection with traditional herbs. Antiviral Res. 1996;32:63-70.

14. Badmaev $V$, Nowakowski M. Protection of epithelial cells against influenza A virus by a plant derived biological response modifier Ledretan-96. Phytother Res. 2000;14:245-9.

15. Kurokawa M, Nagasaka K, Hirabayashi T, Uyama S, Sato H, Kageyama T, et al. Efficacy of traditional herbal medicines in combination with acyclovir against herpes simplex virus type 1 infection in vitro and in vivo. Antiviral Res. 1995;27:19-37.

16. Oyuntsetseg N, Khasnatinov MA, Molor-Erdene P, Oyunbileg J, Liapunov AV, Danchinova GA, et al. Evaluation of direct antiviral activity of the Deva-5 herb formulation and extracts of five Asian plants against influenza A virus H3N8. BMC Complement Altern Med. 2014;14:235.
17. Gupta PC. Biological and pharmacological properties of Terminalia chebula Retz. (Haritaki)- An overview. Int J Pharm Pharm Sci. 2012;4(Suupl 3):62-8.

18. Juang $L$, Sheu SJ, Lin TC. Determination of hydrolyzable tannins in the fruit of Terminalia chebula Retz. by high-performance liquid chromatography and capillary electrophoresis. J Sep Sci. 2004;27:718-24.

19. Kumar KJ. Effect of geographical variation on contents of tannic acid, gallic acid, chebulinic acid and ethyl gallate in Terminalia chebula fruits. Nat Prod. 2006;2:100-4.

20. Lin LT, Chen TY, Chung CY, Noyce RS, Grindley TB, McCormick C, et al. Hydrolyzable tannins (chebulagic acid and punicalagin) target viral glycoprotein-glycosaminoglycan interactions to inhibit herpes simplex virus 1 entry and cell-to-cell spread. J Virol. 2011;85:4386-98.

21. Lin LT, Chen TY, Lin SC, Chung CY, Lin TC, Wang GH, et al. Broad-spectrum antiviral activity of chebulagic acid and punicalagin against viruses that use glycosaminoglycans for entry. BMC Microbiol. 2013;13:187.

22. Alonso-Salces RM, Korta E, Barranco A, Berrueta LA, Gallo B, Vicente F. Determination of polyphenolic profiles of Basque cider apple varieties using accelerated solvent extraction. J Agric Food Chem. 2001;49: 3761-7.

23. Benthin B, Danz H, Hamburger M. Pressurized liquid extraction of medicinal plants. J Chromatogr A. 1999;837:211-9.

24. Blaho JA, Morton ER, Yedowitz JC. Herpes simplex virus: propagation, quantification, and storage. Curr Protoc Microbiol. 2005; Chapter 14:Unit 14E.1-23.

25. Mosmann T. Rapid colorimetric assay for cellular growth and survival: application to proliferation and cytotoxicity assays. J Immunol Methods. 1983;65:55-63.

26. Cheng HY, Lin TC, Yang CM, Wang KC, Lin LT, Lin CC. Putranjivain A from Euphorbia jolkini inhibits both virus entry and late stage replication of herpes simplex virus type 2 in vitro. J Antimicrob Chemother. 2004;53:577-83.

27. Wachsman MB, Castilla V, de Ruiz Holgado AP, de Torres RA, Sesma F, Coto CE. Enterocin CRL35 inhibits late stages of HSV-1 and HSV-2 replication in vitro. Antiviral Res. 2003:58:17-24

28. Shigeta S, Mori S, Baba M, Ito M, Honzumi K, Nakamura K, et al. Antiviral activities of ribavirin, 5-ethynyl-1-beta-D-ribofuranosylimidazole-4carboxamide, and 6'-(R)-6'-C methylneplanocin A against several orthoand paramyxoviruses. Antimicrob Agents Chemother. 1992;36:435-9.

29. Cheng HY, Lin CC, Lin TC. Antiherpes simplex virus type 2 activity of casuarinin from the bark of Terminalia arjuna Linn. Antiviral Res. 2002:55:447-55.

30. Spear PG. Herpes simplex virus: receptors and ligands for cell entry. Cell Microbiol. 2004;6:401-10.

31. Heldwein $\mathrm{EE}$, Krummenacher $\mathrm{C}$. Entry of herpes viruses into mammalian cells. Cell Mol Life Sci. 2008:65:1653-68.

32. Elion GB. Acyclovir: discovery, mechanism of action, and selectivity. J Med Virol. 1993:Suppl 1:2-6.

33. Baliga MS. Triphala, Ayurvedic formulation for testing and preventing cancer: a review. J Altern Complement Med. 2010;16:1301-8.

34. Hazra B, Sarkar R, Biswas S, Mandal N. Comparative study of the antioxidant and reactive oxygen species scavenging properties in the extracts of the fruits of Terminalia chebula, Terminalia belerica and Emblica officinalis. BMC Complement Altern Med. 2010;10:20.

35. Lee HS, Jung SH, Yun BS, Lee KW. Isolation of chebulic acid from Terminalia chebula Retz. and its antioxidant effect in isolated rat hepatocytes. Arch Toxicol. 2007:81:211-8.

36. Suchalatha S, Shyamala Devi CS. Protective effect of Terminalia chebula against experimental myocardial injury induced by isoproterenol. Indian J Exp Biol. 2004;42:174-8.

37. Malekzadeh F, Ehsanifar H, Shahamat N, Levin M, Colwell RR. Antibacterial activity of black myrobalan (Terminalia chebula Retz.) against Helicobactor pyroli. Int J Antimicrob Agents. 2001;18:85-8.

38. Bag A, Bhattacharyya SK, Chattopadhyay RR. The development of Terminalia chebula Retz. (Combretaceae) in clinical research. Asian Pac J Trop Biomed. 2013;3:244-52.

39. Afshari AR, Sadeghnia HR, Mollazadeh $H$. A review on potential mechanisms of Terminalia chebula in alzheimer's disease. Adv Pharmacol Sci. 2016. doi 10.1155/2016/8964849.

40. Yang Y, Xiu J, Liu J, Zhang L, Li X, Xu Y, et al. Chebulagic acid, a hydrolyzable tannin, exhibited antiviral activity in vitro and in vivo against human enterovirus 71. Int J Mol Sci. 2013;14:9618-27. 
41. Kim JH, Koo YC, Hong CO, Yang SY, Jun W, Lee KW. Mutagenicity and oral toxicity studies of Terminalia chebula. Phytother Res. 2012;26:39-47.

42. Kaur S, Grover IS, Singh M, Kaur S. Antimutagenicity of hydrolyzable tannins from Terminalia chebula in Salmonella thyphimurium. Mutat Res. 1998;419:169-79.

43. Gunness P, Aleksa K, Bend J, Koren G. Acyclovir-induced nephrotoxicity: the role of the acyclovir aldehyde metabolite. Transl Res. 2011;158:290-301.

44. Rao NK, Nammi S. Antidiabetic and renoprotective effects of the chloroform extract of Terminalia chebula Retz. seeds in streptozotocin-induced diabetic rats. BMC Complement Altern Med. 2006;6:17.

Submit your next manuscript to BioMed Central and we will help you at every step:

- We accept pre-submission inquiries

- Our selector tool helps you to find the most relevant journal

- We provide round the clock customer support

- Convenient online submission

- Thorough peer review

- Inclusion in PubMed and all major indexing services

- Maximum visibility for your research

Submit your manuscript at www.biomedcentral.com/submit 